\title{
GÉNERO, RELIGIÓN Y ETNIAS. UN PROYECTO PARA EL MUSEO DE LAS MUJERES DEL MEDITERRÁNEO. ALGUNAS NOTAS
}

\author{
Genoveffa Palumbo \\ Università di Roma Tre \\ (Traducción: Ángeles Cruzado Rodríguez)
}

\begin{abstract}
This article deals with the project of the Mediterranean Women Museum and its commitment with fields of research such as Gender Studies and Women History in the different cultural and religious Mediterranean areas. After a theoretical starting point, and from a historical perspective, it focuses on the necessity of taking into account, above all, the debate that is taking place on the 'Mediterranean' origins - African and Asian included - of a series of European cultures. This original angle of vision would facilitate a re-discussion and an innovative contextualization of the topics above mentioned.

Besides, the new historical and religious studies of women will contribute to a new exegesis and critical interpretation of the Holy Scriptures and Christianity based on a gender and ethnic perspective. From a methodological point of view, women history and its geographical dimension will offer new answers and will subvert conventional stereotypes in the representation of women in both museums and history books.
\end{abstract}

\section{Para una historia religiosa de género entre Europa y el Mediterráneo.}

\section{AlgunAS NOTAS}

El proyecto de construir un museo de las mujeres del Mediterráneo se presenta ciertamente como ambicioso, de no fácil realización y también, naturalmente, problemático en los modos y en las formas de su realización. Aquí se tratarán sólo algunos aspectos de esta temática tan compleja. Se señalarán algunos entre los principales problemas, a nivel teórico, que no pueden no plantearse a propósito de tal cuestión. Dejando el tema, para nada secundario, de la delimitación geográfica de los países "mediterráneos", se propondrán, sobre todo, algunas notas sobre la necesidad de tener en cuenta antes que nada el debate sobre los orígenes "mediterráneos" en una perspectiva histórica de género de larga duración, y por tanto, afroasiáticos, de varias culturas europeas, y cómo ésta perspectiva, que ha ido modificando muchas de las adquisiciones, principalmente en el ámbito de la

\footnotetext{
${ }^{1}$ Sobre las ambigüedades de todo discurso sobre el Mediterráneo en la misma concepción de Braudel, consúltese: "Le frontiere dell'Europa e l'antropologia mediterranea", en A. De Clementi (ed.), Il genere dell'Europa. Le radici comuni della cultura europea e l'identità di genere, "Biblink", 3, 2003, pp. 197- 226.
} 
historia religiosa de género, puede encontrar en una exposición museística una ocasión importante de rediscusión y contextualización ${ }^{2}$.

Quizás en ningún lugar como en los países del Mediterráneo, la diversidad de las situaciones en que viven las mujeres sea más variada, más difícil de definir y más unida a la pertenencia religiosa. Es sobre todo por esta razón por lo que toda investigación relativa al mundo femenino, mientras por un lado apela a la constante necesidad de una profundización documental, por el otro nos empuja con creciente insistencia a reflexionar sobre la posibilidad real del uso, por parte de las mujeres de los países no occidentales - o, mejor dicho, fuera del área americana - de las categorías culturales elaboradas en occidente. Se trata, pues, de un problema que presenta dos aspectos bien definidos: por un lado, una necesidad, diremos, documental, de recogida e interpretación de datos, y por el otro la necesidad de una aclaración de naturaleza metodológica y de planteamiento.

No son pocos, pues, los problemas que se están volviendo a proponer, en estos años, sobre todo a nivel teórico, a la atención de los estudiosos y, en particular, de las estudiosas: tales son sobre todo los conflictos entre la libertad religiosa y los derechos de las mujeres y, más en general, entre las normas de los derechos humanos y el respeto de los valores de la identidad cultural y religiosa, entre nuestro concepto de ciudadanía y la universalidad de los derechos $^{3}$. Si bien estos problemas valen, naturalmente, para todos, es precisamente en relación a las mujeres cuando asumen los significados, hoy, más dramáticos y de más compleja solución.

Por tanto, por todas esta razones, todo proyecto relativo a una exposición museística centrada en la historia religiosa de género se encontrará en la necesidad prioritaria de reformular, en una perspectiva histórica de larga duración y teniendo en cuenta esta mutada sensibilidad, los temas clásicos relativos a la historia de las mujeres y del género, antes incluso de afrontar los problemas específicos de tipo "museológico".

\footnotetext{
${ }^{2}$ Véanse sobre todo J. Clifford y G.E. Marcus (eds.), Scrivere le culture. Poetiche e politiche in etnografia, tr. it. Roma, Meltemi 1997; U. Narayan, Dislocating Cultures: Identities, Traditions and Third World Feminism, New York, Routledge, 1997, que se detiene, además, en las acusaciones de haber renegado de su propia pertenencia cultural, dirigidas a las mujeres de los llamados países en vías de desarrollo que abrazan instrumentos de análisis "feministas". En una perspectiva culturalmente más amplia, aunque no específicamente de género pero fundamental para un acercamiento al mundo de los orígenes de la civilización "occidental", crf. M. Bernal, Black Athena: The Afroasiatic Roots of Classical Civilization, New Brunswick (N. J.), University Press, 1987-1990. Sobre cómo esta cuestión no se refiere sólo a la historia de las mujeres, cfr. G. Palumbo, "Le muse inquietanti. Note su un progetto per un museo di storia delle donne", en Vivencia. Conoceré la vita da una generazione all'altra, Rosenberg \& Sellier, Torino, 2003, pp. 280- 287.

${ }^{3}$ Véase, sobre este interesante tema, además de M. C. Nussbaum, Diventare persone. Donne e universalità dei diritti, Bologna, Il Mulino, 2001, pp. 207 y ss. (Il ruolo della religione), P. Weithman (Ed.), Religion and Contemporary Liberalism, Notre Dame, Ind., University of Notre Dame Press, 1997; S Bartoloni (ed.), A volto scoperto. Donne e diritti umani, Roma, Manifesto libri, 2002; más en particular, sobre la diversidad de la problemática religiosa según las pertenencias, cfr. sobre todo L. Cahill, Sex, Gender and Christian Ethics, Cambridge, Cambridge University Press, 1996; J. Plaskow, Standing Again at Sinai: Judaism from a Feminist Perspective, San Francisco, Harper, 1990; A. Y. Al-Hibri, "Is Western Patriarchal Feminism Bad for Third World I minority Women?", Is Multiculturalism Bad for Women? (J. Cohen, M. Howard y M. Nussbaum, Eds.), Princeton, N. J., Princeton University Press, 1999, pp. 41 y ss.; más en general, véase A. De Clementi, "Égalité o parité. Come ripensare la democrazia" Biblink, 1 (2001), pp. 97- 112.
} 


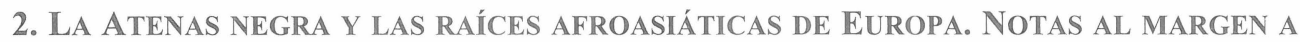 UNA HIPÓTESIS INTERPRETATIVA}

Para quien emprende una investigación histórica, asumir un punto de vista "mediterráneo", quiere decir sobre todo medirse con una serie de problemas que han constituido durante mucho tiempo el argumento de un debate que se ha preguntado sobre los orígenes de la cultura "occidental", contribuyendo a construir la identidad misma de Europa. Al no poder aquí volver a recorrer, ni siquiera sumariamente, la riqueza del mismo debate, me limitaré a incidir sólo en algunos puntos de éste, que se pueden considerar, en cierto sentido, imprescindibles para quien quiere afrontar el problema del género desde esta perspectiva étnico-cultural.

Martín Bernal bien sintetizaba, en el título de un interesante artículo de no hace muchos años (Bernal 1989: 69-133), los términos más importantes de este problema: lo que ha caracterizado a la historia europea en los últimos dos siglos ha sido la negativa a considerar la aportación fundamental que a la civilización y a la cultura europeas había llegado desde la otra orilla del Mediterráneo, es decir, desde las civilizaciones afroasiáticas: la egipcia, mucho más antigua y desarrollada, y las de Oriente Medio. Mientras que durante los largos siglos del Medioevo la centralidad de la cultura bíblica había favorecido en muchos aspectos soluciones orientadas a encontrar, aunque fuera en las recurrentes conflictividades, un sustancial acuerdo entre el relato de las Escrituras y las tradiciones de la Antigüedad clásica (entre mundo "semítico" y mundo europeo que se unía al de la Antigüedad clásica, sobre todo a través de la mediación cristiana), dejando traslucir en el hacerse secular de las distintas identidades europeas influencias y compenetraciones, en un determinado momento este "modelo antiguo" había comenzado a no ser ya constante y uniformemente aceptado. Entonces Europa se había encaminado a la construcción de otro modelo cultural situado totalmente a este lado del Mediterráneo y había comenzado a identificarse con un mundo cada vez más separado y "otro". Entre los siglos XVIII y XIX este proceso de separación había alcanzado ya, según este análisis histórico, su cumbre ${ }^{4}$.

Que la tesis de Bernal, incluso con todas las necesarias cautelas con que pueda ser acogida, presenta indudables elementos de fascinación, sobre todo para quien se ocupa de historia religiosa de género, parece fuera de toda duda. Que puede ofrecer muchas ideas para reformular varios recorridos de historia religiosa en una nueva perspectiva que logre finalmente conjugar los problemas de un correcto enfoque étnico y los relativos al género, parece igualmente indudable. Es difícil, hoy, hablar de Europa o del Mediterráneo, tratar de rediseñar los confines culturales y religiosos a través de una exposición museística, sin tener en cuenta una perspectiva de ese tipo.

\footnotetext{
${ }^{4}$ Varios son, naturalmente, los elementos que han concurrido en este cambio de perspectivas. Por un lado, la laicización ha conllevado una puesta entre paréntesis cada vez más significativa del valor histórico stricto sensu del dictado bíblico, y un abandono de las tentativas de acuerdo entre las cronologías de los distintos pueblos y los relatos de las Escrituras. Por otro lado, el paralelo crecimiento del "mito" helénico ha creído individuar en la civilización griega de los orígenes los caracteres de una cultura en nada tributaria de otros pueblos mediterráneos. Sobre cómo el instrumento de la alegoría ha sido fundamental en estas mediaciones culturales, véanse, desde dos puntos de vista distintos, el estudio de J. Seznec, La sopravvivenza degli antichi dei. Saggio sul ruolo della tradizione mitologica nella cultura e nell 'arte rinascimentali, trad. it. Milano, Boringhieri, 1981, y el debate sobre los jesuitas y la "bella prisionera" G. Palumbo, Speculum peccatorum. Frammenti di storia nello specchio delle immagini tra Cinque e Seicento, Napoli, Liguori, 1990, pp. 207 y ss.
} 
Piénsese antes que nada en la renovada exégesis de la Sagrada Escritura, donde el punto de vista de género ya ha operado profundas transformaciones, y donde, por tanto, una perspectiva étnicamente remodulada podrá rediseñar escenas, personajes y recorridos de investigación que una exposición museística podría traducir en imágenes, textos y documentos. Se reconstruirían así vivencias de personajes, sobre todo femeninos, ausentes en la Sagrada Escritura, pero presentes en las tradiciones apócrifas de los distintos pueblos: desde la primera mujer nacida en el mundo, que una muy difundida tradición común a hebreos cristianos y musulmanes consideraba gemela de Caín, a todas las mujeres de los primeros patriarcas, también ellas generalmente ignoradas por la Biblia, pero presentes en las tradiciones culturales de un área geográfica muy vasta, y que se convierten en objeto, sobre todo entre los siglos XVII y XVIII, de muchas disputas en Europa ${ }^{5}$. Piénsese en el peso de las tradiciones relativas a las primeras representaciones, masculinas y sobre todo femeninas, de los nuevos arquetipos de toda la Humanidad (los hijos de Noé con sus respectivas mujeres) en la formulación del modelo del "pueblo elegido", a través de la tradición bíblica de la maldición de Cam, y de la primera representación de la diversidad étnica como inferioridad de los negros ${ }^{6}$.

También la lectura del cristianismo, en una perspectiva de género "étnicamente" remodulada, aparecería en muchos aspectos con una luz nueva: piénsese en una colección sobre los testimonios de la primitiva iconografía todavía no helenizada de Cristo y en las que representaban a la Virgen María como una joven mujer que llevaba sobre la túnica los dibujos que indicaban, con toda probabilidad, su pertenencia a un específico pueblo siriopalestino (Gharib, 1987: 80). Se delinearían, según esta nueva perspectiva, los recorridos de una tradición religiosa, profundamente modificada por una mujer "sirio-fenicia de nación", la Cananea, tradición que está en la base del nacimiento del cristianismo - en oposición al

\footnotetext{
${ }^{5}$ Para algunos de estos argumentos, y sobre todo en relación con la tradición de la primera mujer nacida en el mundo, hija de Adán y Eva, de cuya difusión muy vasta también da testimonio la gran variedad de nombres con los que es conocida en las diversas tradiciones de los pueblos, cfr. G. Palumbo, "L'archetipo oscuro e dimenticato della sorella. Calmana, sorella di Caino", Quaderni Storici, 1994, 87, pp. 669- 700.

${ }^{6}$ Para las líneas esenciales de las tradiciones hebraica, cristiana y musulmana sobre estos personajes, cfr. M. Bocian, Grande dizionario illustrato dei personaggi biblici, tr. it. Casale Monferrato, 1991. Para las cuestiones de interpretación, cfr. Biblia sacra, Antwerpiae, I. Meursium, 1634; R. Simon, Le grand dictionnaire de la Bible, Lyon, 1740, y P. Bayle, Dictionnaire historique et critique (1697), Basilea, 1741. Sobre las lecturas del pasaje bíblico sobre la maldición de Cam que debía también justificar la esclavitud de los Cananeos, cfr. R. Graves y R. Patai, I miti ebraici, tr. it. Milano, Tea, 1988, pp. 148- 150. Sobre las imágenes de los hebreos cfr., en general, B. Blumenkranz, Le Juif médiéval au miroir de l'art chrétien, Paris, 1966; G. Piccaluga, Ebrei nell'iconografia del 400, en "Rassegna mensile d'Israel", (LII), 2-3, 1986. También la mujer de Noé era un personaje bien conocido en la tradición apócrifa y de ella nos habla por ejemplo el Libro dei Giubilei (cfr. Apocrifi dell'Antico Testamento, (P. Sacchi, Ed.), Torino, Utet, 1989, I, p. 240); y junto a una imagen positiva (cfr. R. Simon, Le grand dictionnaire, cit., II, p. 236), existe también una mucho más ambigua; cfr. J.A. Fabricius, Codex pseudoepigraphus Veteris Testamenti, Hamburgi et Lipsiae, 1713, p. 274; sobre la nuera de Noé, cfr. ivi., p. 278, que ve en ella a la Sibila persa; para una cita orgánica de los mitos relativos también a otras mujeres culpables de magia, en particular la mujer de Noé (Emmezara) y la mujer de Lot (Idith), cfr. R. Graves y R. Patai, I miti, cit., pp. 138- 158. Para todas las otras citas, y sobre todo en relación a la iconografía femenina, cfr. G. Palumbo, "Alle origini della diversità. Annotazioni sull'immagine della donna ebrea", Le Donne delle minoranze: Le ebree e protestanti d'Italia (C. E. Honess, y V. Jones, Eds.), Torino, Claudiana, 1999, pp. 125- 133.
} 
antiguo hebraísmo - como religión abierta, en una perspectiva misionera, a los demás pueblos ${ }^{7}$.

Siempre sobre esta perspectiva femenina étnicamente repensada, se pueden encontrar las líneas de una historia del cristianismo como "religión de las cosas" favorecida por una mujer de Bitinia, Elena, la madre del emperador Constantino, que, según una tradición secular, habría dado un extraordinario impulso al culto de reliquias y objetos sacros en un cristianismo que acababa de ponerse en marcha hacia una institucionalización de larga duración $^{8}$. Lo que se va delineando poco a poco al margen de tales investigaciones, es la imagen de un cristianismo continuamente reinventado por las mujeres: por peregrinas infatigables, que desde la península ibérica o desde Suecia, desde Italia o desde la misma Tierra Santa, han trazado infinitos recorridos entre Europa y el Mediterráneo (Cfr. Silvestre y Valerio, 1999) así como por las santas más diversas que las distintas culturas han producido durante siglos y que una investigación sobre las fuentes del calendario, diversificadas según los países y las distintas Iglesias - desde la griega ortodoxa hasta la católica, desde la armenia hasta la copta, por citar sólo algunas - podrá ayudar a repensar en una perspectiva de género renovada ${ }^{9}$.

\section{Problemas rellativos al género y a la museística. Algunas obServaciones}

Paralelamente a la exigencia de recoger una suficiente documentación sobre estos mundos tan vecinos geográficamente y en los que una mirada histórica descubre a veces sorprendentes afinidades, pero también fragmentos profundos de diversidad, sobre todo para ciertos aspectos del femenino, crecen, y no podría ser de otra manera, dudas metodológicas más específicamente dirigidas también a problemas de preparación y museística sobre las cuales convendrá reflexionar ${ }^{10}$. Sin embargo, por lo demás, es quizás

\footnotetext{
${ }^{7}$ Por eso es recordada la Cananea el segundo domingo de cuaresma, llamado precisamente Dominica Chananeae. Los fragmentos evangélicos sobre la mujer cananea donde el mensaje cristiano se mostraba más abierto y flexible eran los de Mateo, 15, 21, y Marcos, 7, 26; sobre la Cananea cfr. F. Quéré, Le donne nel vangelo, tr. it. Milano, Rusconi, 1983, pp. 76- 87; F. E. Schüsser, In memoria di lei, tr. it., Torino, Claudiana, 1990; G. Palumbo, "I miracoli promessi e negate. Le Meditationes di Nadal tra le domande della donna cananea e le parabole missionarie", Il Pubblico dei santi (P. Golinelli, Ed.), Roma, Viella, 2000, pp. 285- 319.

${ }^{8}$ Sobre Elena y sobre la tradición del viaje a Jerusalén para descubrir y llevar a Roma la cruz de Cristo, el pesebre del nacimiento de Jesús y todos los objetos ligados, no sólo a la persona de Cristo, sino a la tradición cotidiana del cuidado femenino, como, viceversa, para un examen de las razones que harían excluir el hallazgo real de la cruz, cfr. F.E. Consolino, "La 'santa' regina da Elena a Galla Placidia nella tradizione dell'Occidente latino", Vicende e figure femminili in Grecia e a Roma (R. Raffaelli, Ed.), Ancona, "Commissione per le pari opportunità della Regione Marche", 1995, pp. 467- 492; Ead., "Elena, la locandiera”, Roma al femminile (A. Fraschetti, Ed.), RomaBari, Laterza, 1994, pp. 187- 212; Ead., "L'invenzione di una biografia: Alamanno di Hautvillers e la vita di sant'Elena", Hagiographica, 1994, 1, pp. 81-100; A. Amore, "Elena", Biblioteca Sanctorum, Istituto Giovanni XXIII della Pontificia Università Lateranense, Roma, 1961 ss, IV, pp. 988- 992. Sobre este tema cfr. también J. Willem Drjivers, Helena Augusta. The Mother of Constantine the Great and the Legend of Her Finding of the Cross, Leiden, Brill, 1922; G. Palumbo, Giubileo Giubilei, Pellegrini e pellegrine, riti, santi, immagini per una storia dei sacri itinerari, Roma, Rai-Eri, 1999, pp. 353 y ss. También Elena es venerada como santa, el 18 de agosto, por la Iglesia Católica, y el 21 de mayo, junto a Constantino, por la Iglesia Ortodoxa.

${ }^{9}$ Sobre las fuentes del calendario reconstruidas desde un punto de vista de género está en curso una investigación por parte de quien escribe.

${ }^{10}$ Sobre cómo la ampliación de las fuentes tradicionales que ha caracterizado desde su orígenes a la historia de las mujeres puede ayudar a plantear también en sentido metodológicamente correcto muchos de los problemas que
} 
desde el punto de vista de la visibilidad y de la fruición desde donde la ahora ya también experimentada riqueza metodológica de la historia de las mujeres, conjugándose con la ampliación de los horizontes geográficos de la investigación, podrá ofrecer soluciones nuevas que permitirán también afrontar con menores dificultades las actuales perspectivas étnicamente más complejas ${ }^{11}$.

En el debate cultural de estos años están surgiendo algunos interesantes intentos de mostrar la manera estereotípica en que las mujeres son generalmente representadas en los museos. Como en la mayor parte de los manuales de historia, en los museos, la vida, el trabajo y el pensamiento de las mujeres resultan sobreentendidos, escondidos, o, viceversa, como anómalos (Cfr. Porter 1987, 22: 11-15; Kavanagh, 1994: 370-375; Tota, 1999). En cambio, un museo nuevo, que nazca del corazón mismo de la investigación de historiadoras e historiadores de las mujeres de los distintos países y de las distintas tradiciones culturales y religiosas podría, por un lado, concretamente mostrar todo lo que una rica estratificación ya ha acumulado desde los lejanos debates sobre el "matriarcado" en términos de objetos, pensamientos, ideas y problemas, en torno a la historia de las mujeres; por otro lado, podría ayudarnos a comprender mejor el concreto hacerse histórico de las diversidades que han atravesado, también desde el punto de vista "femenino", los mundos mediterráneos ${ }^{12}$.

Cuando un debate cultural ha alcanzado, como sucede con el relativo al género, un corpus documental / monumental significativo y al mismo tiempo presenta problemas todavía abiertos, la museización, con sus intentos de transposición en términos de lenguaje visual de cada problema de interpretación, con la comparación que cada exposición necesariamente conlleva, no puede sino proporcionar una gran ayuda a la reflexión. Por tanto, para la historia de las mujeres y, más en general, para la cultura de género, no sólo es posible, sino ciertamente auspiciable, una museización que favorezca un cambio crítico de opinión y un encuadramiento dentro de los parámetros geográficamente más amplios del debate cultural de nuestros días. Bien en términos de profundización de un recorrido de investigación, bien en términos de recaída social, la transformación en museo aparece como un recorrido con interesantes perspectivas.

Por lo demás, son varias las experiencias de museos "en femenino" sobre las que podemos empezar a reflexionar, y los museos europeos de las mujeres se presentan como muy diferentes entre sí: desde el Frauenmuseum de Bonn, hasta los de Wiesbaden o Aarhus

\footnotetext{
surgen del estudio de modos femeninos y masculinos culturalmente diversos, cfr. también G. Palumbo, Le muse inquietanti, cit., pp. 282- 283.

${ }^{11}$ Sobre la historia de las mujeres, cfr. también S. Manzini, "La storia delle donne in Italia: percorsi culturali e nuove proponte negli attuali indirizzi storiografici", Annali di Storia moderna e contemporanea, 1997, 3, pp. 349381; A. De Clementi, "Sulla storia delle donne in Italia", Le donne e la storia. Problemi di metodo e confronti storiografici (M. Pelizzari, ed.), Napoli, Esi, 1995, pp.17- 26.

${ }^{12}$ Las referencias son, por un lado, las relativas al ya lejano concepto de matriarcado de Jacob Bachofen (Il Matriarcado, tr. it. Torino, Einaudi, 1988), y por otro las delineadas en F. Braudel, Civiltà e imperi del Mediterraneo nell'età di Filippo II, tr. it. Torino, Einaudi, 1986 (ed. or. 1949); en lo que respecta a la investigación sobre la cultura material y más en general el mundo de los objetos dentro del que se inscribe un recorrido de género, cfr. sobre todo Id., Le strutture del cuotidiano, tr. it. Torino, Einaudi, 1982 (1 ${ }^{\mathrm{a}}$ ed. 1979); entre las publicaciones más recientes, véase R. Sarti, Vita di casa. Abitare, mangiare, vestire nell'Europa moderna, Roma-Bari, Laterza, 1999, sin olvidar las diversas publicaciones sobre la vida privada; no es preciso añadir que un punto particularmente significativo de esta investigación será el dirigido a individuar bibliografías específicas de cada área geográfica.
} 
en Dinamarca, nacidos todos en los primeros años 80, desde el austriaco de Hittisau hasta los pequeños museos en el Lago de Garda y en Bolzano, el punto de vista de las mujeres europeas ha encontrado varias formas, muy distintas, de museización, todas dignas de ser estudiadas. Partiendo, pues, de las experiencias concretas ya realizadas por éstos y por otros museos, todos lejanos de la centralidad mediterránea, sería muy importante comenzar a ordenar nuestras reflexiones y empezar a pensar en un museo del todo nuevo, donde los temas del femenino se entrecrucen constantemente con las antiguas demandas que el enfrentamiento entre religiones y culturas vuelve a proponer hoy a la investigación ${ }^{13}$.

Desde la época de los primeros museos de la edad moderna, muchos temas han sido objeto de museización. Las tensiones sociales que a veces han acompañado a la organización de algunas exposiciones, y sobre todo de algunas exposiciones "étnicas", indican suficientemente la existencia de una conciencia difusa del rol desempeñado por los museos en la construcción social de las identidades culturales. Frente al entramado de estas identidades culturales toda museización se presenta hoy como un interesante recorrido de investigación de fuerte repercusión social ${ }^{14}$.

Por tanto, intentar una museización puede ayudarnos a reflexionar, en una óptica más ampliamente cultural, sobre temas del femenino y a la vez a recoger una documentación, por así decirlo, concretamente visible de la diversidad que atraviesan los mundos de las mujeres. Sobre todo, un proyecto de museo nos obliga a interrogarnos sobre cuál es la historia de las mujeres que se quiere museizar o, mejor dicho, la historia de qué mujeres se esconde bajo la aparente neutralidad de las mujeres tout court sobre las que, según el caso, se discute.

Muchos son los museos que, en Italia y en el mundo, ven crecer, una estación tras otra, el número de visitantes: museos arqueológicos y de artes figurativas, museos de las tradiciones populares y museos de la ciencia, por citar sólo algunas de las más difundidas tipologías. Exposiciones museísticas pequeñas y grandes se van creando espacios cada vez más especialistas, y atraen al mismo tiempo a masas deseosas de ver, saber y conocer. Sin embargo, el museo no siempre logra satisfacer, hoy, este deseo de saber. A menudo la oferta no está adecuada a la demanda porque propone modelos en desuso de un saber inmóvil afectados por una crónica separación, o porque ofrece fragmentos de una cultura altamente especializada que la mayoría de los visitantes no logra contextualizar.

\footnotetext{
${ }^{13}$ Entre las más interesantes reflexiones sobre estas experiencias museísticas y, más en general, sobre los problemas que una museización centrada en el femenino plantea, cfr. N. Heller, (Ed.), Women Artists: Works from the Nacional Museum of Women in the Arts, Rizzoli, 2000; R. Muttenthaler, H. Posch, E.S. Sturm, (Eds.), Seiteneingänge Museumsidee \& Ausstellungsweisen, Wien, Verlag Turia+Kant, 2000; G. Haven, R. Muttenthaler, Das Inszenierte Geschlecht. Feministische Strategien im Museum, Wien, Böhlau, 1997; C. Battersby, Gender and Genios: Toward a Feminist Aesthetics, Londres, Women's Press, 1990; G. Porter, Gender, cit.; Id., "Seeing through Solidiy: a Feminist Perspective on Museum", Theorizing Museums. Representing Identitiy and Diversity in a Changing World (S. Macdonald, y G. Fyfe), Oxford, Blackwell, 1996, pp.105-126; H. Riegel, Into the Heart of Irony: Ethnographic Exhibitions and the Politics of Difference, ivi, pp. 83- 104.; T. De Lauretis,, Technologies of Gender. Essays in Theory, Film and Fiction, Bloomington, Indiana University Press, 1987; G. Salvatori, "La sindrome delle Muse", Donna, filosofia e cultura nel Seicento (P. Totaro, Ed.), Roma, CNR, 1999; más en general, cfr. P. Bordieu et alii, L'amore dell'arte. Le leggi della diffusione culturale. I musei d'arte europei e il loro pubblico, tr. it. Rimini, Guaraldi, 1973.

${ }^{14}$ Cfr. A. Tota, Sociologie, cit., pp. 121 y s.; I. Karp, C. Mullen Kreamer y S.D. Lavine, (Eds.), Musei e identità. Politica culturale delle collettività, tr. it. Bolonia, Clueb, 1995; G. Kavanagh, Looking, cit.
} 
Universidad, escuela, televisión, mundo virtual y museo son mundos separados y despegados. Al progreso en muy diversos campos del nivel de profundización científica de un debate cultural no corresponde, en la realidad, un progreso de la explosión museística ${ }^{15}$.

También los finos y esenciales hilos que ligan un museo al territorio en el que surge son a menudo muy frágiles. Si, por un lado, muchos son los saberes que ya han constituido un corpus significativo de profundización y a los cuales no corresponde un museo que les dé su justa visibilidad, por otro lado, el concepto mismo de museo como un lugar que quita el objeto de su contexto natural para hacerlo entrar en un mundo ficticio de pura visibilidad plantea desde hace tiempo más que justos interrogantes. Se ha dicho que el museo, más que "lugar cerrado", hay que entenderlo como coordinación sobre el territorio de bienes que reclaman una dignidad cultural: ya no tanto una celebración del saber, sino sobre todo una apropiación de éste (Basso Peressut, 1985). Y es precisamente para favorecer la apropiación, por parte de las mujeres y de los hombres de distintas procedencias culturales, para lo que se propone la realización de un museo que en esa cultura "mediterránea" se esfuerce para reencontrar no sólo los rasgos comunes, sino, más específicamente, los posibles, comunes, recorridos de género.

La constitución de un museo de la historia de las mujeres del Mediterráneo responde, pues, ante todo, al objetivo de ofrecer visibilidad a los saberes ligados a la historia de las mujeres. La elección del ámbito geográfico, centrado en el Mediterráneo, del museo trata de inscribir la investigación de género en un horizonte histórico cultural que para una antiquísima tradición está ligado a un sistema simbólico modulado, de distintas maneras, "en femenino". Proponer recoger en una ciudad mediterránea los testimonios de la vivencia histórica femenina común al Mediterráneo como lugar simbólico antes incluso que lugar geográfico, significa también dotar a las mujeres y a los hombres de un instrumento ciertamente útil para descifrar, contextualizándolo en un horizonte más vasto, su pasado: su pasado común y su pasado diferente. Nada más que un museo hace visibles y concretas las realidades culturales que quiere representar, $y$, al representarlas, contribuye al mismo tiempo a deconstruirlas.

Este museo, que se vale no sólo de las tradicionales técnicas expositivas, sino también de todos aquellos enlaces virtuales que pueden hacer disfrutar un objeto sin sustraerlo de su contexto natural, se situará en el centro de una red de enlaces que trata de restablecer las relaciones entre museo y territorio, museo, instituciones culturales y mundo multimedia, que no sólo garantizan su constante integración con los aparatos más diversos de la sociedad civil, sino que hacen también de él un centro de alta formación y de empleo de personal con distintos grados de especialización en una renovada ciencia museológica ${ }^{16}$; un

\footnotetext{
${ }^{15}$ Véanse, en general, A. Abruzzese, "Viaggio di ritorno: innovazioni tecnologiche e linguaggi espressivi", Rassegna Italiana di Sociologia, 1992, XXXIII, pp. 535-572; F. Antinucci, "Museo e nuove tecnologie: dov'è il problema?", Sociologia del lavoro, 1985, 25, pp. 200-223; L. Arestizábal, .y A. Piva, Musei in trasformazione. Prospettive della museologia e della museografia, Milano, Mazzotta, 1991.

${ }^{16}$ Sobre la acentuación filosófico-proyectista de la museología, así como sobre las características técnico-prácticas de la museografía moderna, cfr. I. Arestizábal, y A. Piva, Musei in trasformazione. cit.; cfr. también A. Lugli, "Discipline museali, museologia, museografia", Il museo (R. Schaer), Electa Gallimard, 1996 (ed. or. Paris, 1993), pp. 158-159. Más ligado al concepto de proyecto están los estudios de museotécnica: desde el análisis del espacio museístico como "contenedor" en relación a las categorías de los objetos contenidos, al control de los parámetros ambientales (iluminación, señalética a la comunicación, seguridad, etc.).
} 
centro donde todo aquello que no se pueda real y concretamente recoger, se mostrará en unión virtual; un museo que tutele y valorice el patrimonio cultural de la historia de las mujeres conservando las huellas de las tradiciones y del trabajo femenino, de la cotidianidad de los gestos de cuidado de las mujeres en los distintos contextos habitacionales y de los objetos que han acompañado su vida.

Se tratará, sin embargo, de un museo que sepa recoger, documentar y mostrar también las conquistas de ciudadanía de las mujeres donde éstas se han realizado, y que ayude a comprender, a través de una puntual y precisa documentación, las razones de su fallida actuación allí donde éstas difícilmente encuentran cumplimiento; un museo que recoja, actualizando constantemente sus catálogos, las escrituras femeninas, pero un museo que también sea capaz de recoger los testimonios de las mujeres sin escritura de los países europeos y mediterráneos de ayer y de hoy; un museo que recoja objetos y documentos de los ritos de la maternidad, pero que se pregunte sobre las formas y sobre los modos de vivir y trabajar de las mujeres solas; un nuevo museo-templo-de-las-musas, aunque sea de musas inquietantes a la manera del novecientos y, querría añadir, "a la manera femenina", según la bella composición de la obra homónima de Isabella Ducrot, pues evocándola me gustaría cerrar esta intervención ${ }^{17}$.

\section{REFERENCIAS BIBLIOGRÁFICAS}

ABBRUZZESE, A., "Viaggio di ritorno: innovazioni tecnologiche e linguaggi espressivi", Rassegna Italiana di sociologia, 1992, XXXIII, pp. 535- 572.

AL-HIBRI, A.Y., "Is Western Patriarchal Feminism Bad for Third World / minority Women?", Is Multiculturalism Bad for Women? (J. Cohen, M. Howard y M. Nussbaum, eds.), Princeton, N. J., Princeton University Press, 1999.

AMORE, A., "Elena", Biblioteca Sanctorum, Istituto Giovanni XXIII della Pontificia Università Lateranense, Roma, 1961 ss., IV, pp. 988- 992.

ANTINUCCI, F., “Musei e nuove tecnologie: dov'è il problema?", Sociologia del lavoro, 1985, 25, pp. 200- 223.

ARESTIZABAL, L. y PIVA, A., Musei in trasformazione. Prospettive della museologia e della museografia, Milano, Mazzotta, 1991.

BACHOFEN, J., Il Matriarcato, tr. it. Torino, Einaudi, 1988.

BARTOLONI, S. (ed.), A volto scoperto. Donne e diritti umani, Roma, Manifesto libri, 2002.

BASSO PERESSUT, L., (ed.), I Luoghi del museo. Tipo e forma fra tradizione e innovazione, Roma, Editori Riuniti, 1985.

BATTERSBY, C., Gender and Genius: Towards a Feminist Aesthetics, London, Women's Press, 1990.

BAYLE, P., Dictionnaire historique et critique (1697), Basilea, 1741.

\footnotetext{
${ }^{17}$ El primer paso, para comenzar a reflexionar sobre este proyecto ha sido la institución, en el "Istituto Italiano degli Studi Filosofici" de Napoli, de un curso de Museología de género e historia de las mujeres, que desde el mes de noviembre de 2001 viene funcionando. Para la composición de Isabella Ducrot, véase Isabella Ducrot, 19892002 (P. Tognon, ed.), Milano, Silvana editoriale, 2002, n. 1, Muse inquietanti, 1989.
} 
BERNAL, M., Black Athena: The Afroasiatic Roots of Classical Civilization, New Brunswick (N. J.), University Press, 1987- 1990.

BERNAL, M., "Il ripudio della Atena nera e delle radici afro-asiatiche dell'Europa", Comunità 191/192, 1989, pp. 69- 133.

Biblia sacra, Antwerpiae, I. Meursium, 1634.

BLUMENKRANZ, B., Le Juif médiéval au miroir de l'art chrétien, Paris, 1966.

BOCIAN, M., Grande dizionario illustrato dei personaggi biblici, tr. it. Casale Monferrato, 1991.

BORDIEU, P., et alii, L'amore dell'arte. Le leggi della diffusione culturale. I musei d'arte europei e il loro pubblico, tr. it. Rimini, Guaraldi, 1973.

BRAUDEL, F., Civiltà e imperi del Mediterraneo nell'età di Filippo II, tr. it. Torino, Einaudi, 1986 (ed. or. 1949).

BRAUDEL, F., Le strutture del quotidiano, tr. it. Turín, Einaudi, 1982 (ed. or. 1979).

CAHILL, L., Sex, Gender and Christian Ethics, Cambridge, Cambridge University Press, 1996.

CLIFFORD J. y MARCUS, G. E., (eds.), Scrivere le culture. Poetiche e politiche in etnografia, tr. it. Roma, Meltemi, 1997.

CONSOLINO, F. E., "La 'santa' regina da Elena a Galla Placidia nella tradizione dell'Occidente latino", Vicende e figure femminili in Grecia e a Roma (R. RAFFAELLI, ed.), Ancona, Commissione per le pari opportunità della Regione Marche, 1995, pp. 467- 492.

CONSOLINO, F. E., "Elena, la locandiera", Roma al femminile (A. FRASCHETTI, ed.), Roma-Bari, Laterza, 1994, pp. 187- 212.

CONSOLINO, F. E., "L'invenzione di una biografia: Alamanno di Hautvillers e la vita di sant'Elena", Hagiographica, 1994, 1, pp. 81- 100.

DE CLEMENTI, A., "Sulla storia delle donne in Italia", Le donne e la storia. Problemi di metodo e confronti storiografici (M. Pelizzari, ed.), Napoli, Esi, 1995, pp. 1726.

DE CLEMENTI, A., "Égalité o parité. "Come ripensare la democrazia"”, Biblink, 1, 2001, pp. 97- 112.

DE CLEMENTI, A., (ed.), Il genere dell'Europa. Le radici comuni della cultura europea e l'identità di genere, Biblink, 3, 2003.

DE LAURETIS, T., Technologies of Gender. Essays in Theory, Film and Fiction, Bloomington, Indiana University Press, 1987.

FABRICIUS, J. A., Codex pseudepigraphus Veteris Testamenti, Hamburgi et Lipsiae, 1713.

GHARIB, G., Le icone mariane. Storia e culto, Roma, Città Nuova, 1987.

GRAVES, R. y PATAI, R., I miti ebraici, tr. it. Milano, Tea, 1988.

HAVEN, G. y MUTTENTHALER, R., Das Inszenierte Geschlecht. Feministische Strategien im Museum, Wien, Böhlau, 1997. 
HELlER, N., (ed.), Women Artists: Works from the National Museum of Women in the Arts, Milano, Rizzoli, 2000.

KARP, I., MULLEN KREAMER C., y LAVINE, S.D., (eds.), Musei e identità. Politica culturale delle collettività, tr. it., Bologna, Clueb, 1995.

KAVANAGH, G., "Looking for ourselves, Inside and Outside Museums", Gender and History, 6, 3, 1994, 370- 375.

LAVINE, S. D. y KARP, I., Musei e culture, tr. it. Bolonia, Clueb, 1995.

LUGLI, A., "Discipline museali, museologia, museografia", Il museo (R. Schaer, ed.), Electa Gallimard, 1996 (ed. or. Paris, 1993).

MANTINI, S., "La storia delle donne in Italia: percorsi culturali e nuove proposte negli attuali indirizzi storiografici", Annali di storia moderna e contemporanea, 1997, 3, pp. 349- 381 .

MUTTENTHALER, R., POSCH, H. y STRUM, E. S., (eds.), Seiteneingänge Museumsidee \& Ausstellungsweisen, Viena, Verlag Turia+Kant, 2000.

NARAYAN, U., Dislocating Cultures: Identities, Traditions and Third World Feminism, New York, Routledge, 1997.

NUSSBAUM, M. C., Diventare persone. Donne e universalità di diritti, Bologna, Il Mulino, 2001.

PALUMBO, G., Speculum peccatorum. Frammenti di storia nello specchio delle immagini tra Cinque e Seicento, Napoli, Liguori, 1990.

PALUMBO, G., "L'archetipo e oscuro e dimenticato della sorella. Calmana, sorella di Caino", Quaderni Storici, 1994, 87, pp. 669- 700.

PALUMBO, G., "Alle origini della diversità. Annotazioni sull'immagine della donna ebrea", Le donne delle minoranze: Le ebree e protestanti d'Italia (Honess, C. E. y Jones, V., eds.), Torino, Claudianana, 1999, pp. 125- 133.

PALUMBO, G., Giubileo Giubilei. Pellegrini e pellegrine, riti, santi, immagini per una storia dei sacri itinerari, Roma, Rai-Eri, 1999.

PALUMBO, G., "I miracoli promessi e negati. Le Meditationes di Nadal tra le domande della donna cananea e le parabole missionarie", Il Pubblico dei santi (GOLINELLI, P., ed.), Roma, Viella, 2000, pp. 285-319.

PALUMBO, G., "Le muse inquietanti. Note su un progetto per un museo di storia delle donne", in Vivencia. Conoscere la vita da una generazione all'altra, Torino, ed. Rosenberg \& Sellier, 2003, pp. 280- 287.

PICCALUGA, G., "Ebrei nell'iconografia del '400”, Rassegna mensile d'Israel, (LII), 2-3, 1986.

PLASKOW, J., Standing Again at Sinai: Judaism from a Feminist Perspective, San Francisco, Harper, 1990.

PALUMBO, G., "Seeing through Solidity: a Feminist Perspective on Museum", Theorizing Museums. Representing Identity and Diversity in a Changing World (MACDONALD, S. y FYFE, G., eds.), Oxford, Blackwell, 1996, pp. 105- 126. 
PORTER, G., "Gender Bias: Representation of Work in History Museum", en Bias in Museum (A. CARRUTHERS, ed.), London, Museum Professional Group Transaction, 1987, vol. 22, pp. 11- 15.

QUERE, F., Le donne nel vangelo, tr. it., Milano, Rusconi, 1983.

RIEGEL, H., "Into the Heart of Irony: Ethnographic Exhibitions and the Politics of Difference", Theorizing Museums. Representing Identity and Diversity in a Changing World (Macdonald, S., y Fyfe, G., eds.), Oxford, Blackwell, 1996, pp. 83- 104.

SACCHI, P., (ed.), Apocrifi dell'Antico Testamento, I, Torino, Utet, 1989.

SALVATORI, G., "La sindrome delle Muse", Donna, filosofia e cultura nel Seicento (Totaro, P., ed.), Roma, CNR, 1999, pp. 393- 434.

SARTI, R., Vita di casa. Abitare, mangiare, vestire nell'Europa moderna, Roma-Bari, Laterza, 1999.

SAURER, E., Le frontiere dell'Europa e l'antropologia mediterranea, in Il Genere dell'Europa. Le radici comuni della cultura europea e l'identità di genere, a cura di Andreina De Clemeni, "Biblink", 3, pp. 197- 226.

SCHÜSSLER FIORENZA, E., In memoria di lei, tr. it., Torino, Claudiana, 1990.

SEZNEC, J., La sopravvivenza degli antichi dei. Saggio sul ruolo della tradizione mitologica nella cultura e nell'arte rinascimentali, tr. it. Milano, Boringhieri, 1981.

SILVESTRE, M. L. y VALERIO, A., (eds.), Donne in viaggio. Viaggio religioso, politico, metaforico, Roma-Bari, Laterza, 1999.

SIMON, R., Le grand dictionnaire de la Bible, Lyon, 1740.

TOGNON, P., (ed.), Isabella Ducrot, 1989-2002, Milano, Silvana Editoriale, 2002, n. 1, Muse inquietanti, 1989.

TOTA, A., Sociologie dell'arte. Dal museo tradizionale all'arte multimediale, Roma, Carocci, 1999.

WEITHMAN, P., (ed.), Religion and Contemporary Liberalism, Notre Dame, Ind., Univesity of Notre Dame Press, 1997.

WILLEM DRIJVERS, J., Helena Augusta. The Mother of Constantine the Great and the Legend of Her Finding of the Cross, Leiden, Brill, 1992. 